\title{
Leadership Styles and Job Satisfaction among Employees in Small and Medium Enterprises
}

\author{
Oladipo Kolapo Sakiru ${ }^{1}$, Jeffrey Lawrence D’Silva ${ }^{2}$, Jamilah Othman ${ }^{1}$, Abu DaudSilong ${ }^{1}$ \& Adekanye Temitope \\ Busayo $^{3}$ \\ ${ }^{1}$ Department of Human Resource Development, Faculty of Educational Studies, Universiti Putra Malaysia, \\ Malaysia \\ ${ }^{2}$ Institute for Social Science Studies, Universiti Putra Malaysia, Malaysia \\ ${ }^{3}$ Department of Educational Management, University of Ibadan, Nigeria \\ Correspondence: Jeffrey Lawrence D'Silva, Institute for Social Science Studies, Universiti Putra Malaysia, \\ Malaysia.E-mail: jld@putra.upm.edu.my
}

Received: February 17, 2013

Accepted: April 27, 2013

Online Published: June 17, 2013

doi:10.5539/ijbm.v8n13p34

URL: http://dx.doi.org/10.5539/ijbm.v8n13p34

\begin{abstract}
Investigation into the relationship between leadership styles and job satisfaction among employees in small and medium enterprises in Nigeria is the main focus of this research. The research used survey design to gather data from one hundred and fifteen employees from the small and medium enterprises. The study utilized simple random sampling techniquesand data was collected using a questionnaire that required respondent to rate their level of job satisfactions as well as their "leaders" leadership styles using a five point scale likert type. The result of correlation analysis revealed that the entire leadership styles items are statistically significant at .05 level of significance, also the result of descriptive statisticsindicates transformational leadership styles has the most commonly used leadership styles in the small and medium enterprises in Nigeria.Transformational leaders are needed insmall and medium scale enterprises in Nigeria to be able to achieve the mission, objectives and goals for the development of this enterprisein the country.
\end{abstract}

Keywords: leadership, leadership styles, job satisfaction, organization, small and medium enterprises

\section{Introduction}

Organizations around the globe are deeply worried about thoughtful, examining and evolving leadership. No matter the kind of organization, leadership is discovered to play an important role in creating an effective organization for the success of the organization. Leaders are facing greater challenges than in the past because of the elevated environment complexity and also the altering character from the organization. When we hint back to history, it might be apparent that leaders should be capable of implementing changes With regards to environmental demands.

Leaders are convened the chance to guide, not since they're hired by senior managers they lead since they're professed and recognized by fans as leaders (Boseman, 2008). Actually an innovator needs to supply the fans precisely what it takes to ensure that they're prolific and advance on the way to the common vision. But when the leaders neglect to provide that which was guaranteed before, it flourishes a feeling of disbelief and de-motivation. Thus leaders must be centered on his followers' needs both within and outdoors of the organization to ensure that they are stirring ahead consistently. Another primary quality of the leader is "anticipation". Leaders can anticipate the near future prospects and plan substitute method to satisfy challenges. Such traits are typical in historic leaders. This feeling of anticipation is thought to become innate and cannot be created in managers.

The existence of the organization is for a variety of purposes; some produce goods for local or external consumption while others provide necessary services for profit or community benefits. In pursuit of their goals and objectives, all organizations rely on various levels of plans, and surviving strategies has to be formulated routinely to fix the changing business environment constraint by the available resources available to the organization. Business has variously being defined by various authors and scholars, it has been established that these concepts has different meanings to individuals. Generally, business could be defined according to Lawal (2003) as an action which occupies time and demands attention as oppose to pleasure or recreation. It can further 
be defined as anything one engaged or occupied within a space of time that keep one busy with expectation of tangible return. Business organizations are closely and generally identified as economic institutions, source collection of human and material resources for the purpose of economic production at a profit.

In view of the research gap and lack of information concerning leaders and leadership styles and job satisfaction in SMEs more studies are needed to determine the types of leadership styles adopted in these organizations in the Nigerian context. Following the views presented, this study strived to examine the correlation between leadership styles and job satisfaction among employees in small and medium enterprises and to determine the leadership styles that are commonly used by the leaders in the organization.

\section{Literature Review}

\subsection{Leadership Styles}

Fiction on leadership shows a open-minded pattern, which begins from concentrating on the characteristics and qualities of the leader, now focuses on performance and then stresses around the contextualized character from the leadership.

The idea of leadership begins using the distinctive concentrate on the theory of "Great Man". The advocate from the great man theory accepts that leaders are natural and also have inborn characteristics consequently, leaders can't be prepared. The term "Man" was intentionally accustomed to indicate the function of males only. Firstly, leaders were regarded as individuals getting success tales that have been largely connected with the military males (Bolden, 2004). Even management scholars and organizational researchers continue to be in favor from the great man idea (Organ, 1996). Prompt enquiry on leadership additional shanties light on the most popular traits that differentiate leaders from fans.

The accentuated viewpoint refer to, if anybody has traits for example adaptive, receptive, determined, achievement-orientated, confident, decisive, enthusiastic, insistent, self-confident etc, he at that point is really a leader or prospective leader (Boseman, 2008). Well along the leadership ideas were very likely near behavior styles that leader showed previously. Behavior paradigms were inspired to understand the behavior facets of leaders to ensure that individuals might be competent as leaders (Bolden, 2004).

The following way of thinking came from by means of situational ideas, which presumed that suitable leaders' performance differs from one condition to a different. The very best strategy or leadership behavior is needed in compliance using the situational variable (Griffin, 1999).

Ensuing and virtually related ideas were suggested as contingency theory that was mainly worried about exact environment variables that govern the very best leadership style appropriate with the problem. No constant leadership style is the greatest rather several variables such as the leadership style, characteristics from the fans and facets of the problem show important role in in the main success (Hicks and Gullett, 1987).

Current collected works on leadership mainly concentrates on the two primary size of leadership i.e. transactional and transformational leadership. Transactional leadership is dependant on leader follower exchanges. Followers execute based on the drive and trend from the leaders and leaders absolutely reward the efforts. The standard is compensation which may be undesirable like disciplinary action, if followers neglect to adhere to or it may be encouraging like commendation and acknowledgment, if aides adhere to the committed and path established by the leader and get the given objectives. Four core areas of transactional leadership as referred to by Schermerhorn et al. (2000) are passive management by exception contingent rewards, laissez-faire and passive management by exception.

Another focal point for the majority of the scientists and professionals is transformational leadership which displays another extreme. Transformational leaders affect the values and outlooks of follower and encourage the aides in their specific individual benefits equivalent using the enhancement from the organization (Burns, 1978). Transformational leaders simplify new considerations by growing or changing understanding of matters. Resultantly, they promote stimulation and enthusiasm to place further determinations to attain mutual goals. Based on Burns (1978), transformational leadership is also according to four dimensions for example communication, charisma, individualized consideration and intellectual stimulation. Certain scientists interchangeably use transformational leadership as charming leadership. But based on McLaurin and Al-Amri (2008), numerous variations between both of these positions exist like charisma being one amongst the characteristics of the transformational leader as opposed to the sole component, the result of situational favorableness or improbability on attitudes, transformational behavior de -accentuating charisma, the charming leader's possible self-interest and also the probable unwanted effects of charming leadership (McLaurin and AlAmri, 2008). It's also thought that transformational leadership is much more dominant at superior levels of 
management than at lower level (Tichy and Uhich, 1984).

Tranformational and transactional leadership continues to be of curiosity to a lot of scientists in the present era. Implementing either transactional or transformational leadership performance works well for the prosperity of the organization (Laohavichien et al., 2009). Both transformational leadership and transactional leadership assist in forecasting subordinates' satisfaction by their leaders (Bennett, 2009). This can be why different writers of the past considered transactional and transformational leadership as building variables and looked into their relatedness along with other qualifying criterion variables. However, in certain situations both cannot supply the crucial satisfaction for their subservient and partly lead as explanatory variables. In the same manner the research of Jansen et al. (2009) came to the conclusion the transformational leadership actions lead considerably to empirical innovation while transactional leadership actions facilitate enhancing and stretching existing understanding and therefore are connected with exploitative innovation (Jansen et al., 2009).

As study regarding Chen et al. (2005) discovered that followers were pleased with the contingent reward dimension of transactional leaders and stimulation thought on transformational leaders.

\subsection{Job Satisfaction}

Work plays a huge part in persons' lives simply for the reason that they devote more of time at the office than doing every other single activity. Based on Furnham (2005), one will find a lot of reasons why people work: work supplies a means of earnings, a resource of action and motivation, a resource of social contacts, an easy method of constructing time, along with a supply of self-fulfilment and self-actualisation. Employees' job satisfaction can also be an essential facet of work. Positive feelings in regards to a job can lead to people going through greater satisfaction with their former lifestyle generally. Additionally they lead people to become healthier emotionally and substantially. Work might be a supply of pleasure for a person, and for that reason, researchers yet others who're worried about individuals' pleasure, stress that top job satisfaction ought to be practiced (Spector, 2008).

In the past, the idea of job satisfaction continues to be broadly investigated subsequently to the beginning of the twentieth century, when there is movement in the direction of thinking about the mental circumstances of the worker connected with post-war industrial revolution with regards to growing in the output of employees (Allen and Wilburn, 2002; Mullins, 2004). Because the Hunman relation School was established, the numerous facets of the accompanying concepts of job satisfaction and inspiration happen to be shown through the various job satisfaction and inspirational ideas, for example individuals by Maslow, Herzberg, Vroom and so forth.

Workers are the primary organizational means without workers; organizations would not exist or function (Worthington and Britton, 2006). Recently, calculating workers' satisfaction has turned into a matter of accelerating concern among business managements.

When workers are pleased, they enhance the enactment and output of the organization and lead confidently on the way to success. Based on Wright et al. (2003), the advantages that workers receive using their business impact and skill, effort, productivity and creativeness that they're enthusiastic to offer to their manager. Organisations with content workers surpass other organisations (Ostroff, 1992). Consequently, job satisfaction has turned into a main organisational objective for reasonable amounts of excellence and organisational success.

However, low job satisfaction has negative final results, for example withdrawal behavior, growing costs, lowering profits and, eventually, customer dissatisfaction (Allen, 2002). Based on Spector (1997), workers going through discontent may cultivate troublesome behaviors that adversely effect upon their output and gratifaction, in addition to affecting individuals around them. Concentrating on worker job satisfaction within the place of work is, therefore, answer to comprehending the aspects of workers' behavior as well as their effective role.

Job satisfaction is often as crucial for workers because it is for the organization development. Currently, workers expect to obtain more contentment with their work than in the past. Workers may consider job satisfaction as a means to stay their current organization as a determinant order to change to another (Boseman, 2008). Simultaneously, employees want to be satisfied with their job. Contemporary professionals of human assets management determine an awareness of workers' wants which contest discrete and organizational wants in a way that workers believe that their self-improvement can be done together with the organisation's growth. For this result, organisations cannot attain great decent amounts of consumer support eminence if their employees do not feel satisfied (Boseman, 2008). Quite simply, to have an organisation to possess satisfied clients, it has to first have satisfied workers. Many of the relevant where employees have direct connection with clients.

\section{Method}

The aim of the present research was to gain knowledge on relationship between leadership styles and job satisfaction among Smes employees in an organization. To answer the research objectives in the study, data was 
collected from the employees from two private sectors organization in Lagos, Nigeria. The total number of 160 employees was targeted as the population of the study. All subjects are fully informed as to the nature of the investigation. They are all assured that all the data collected on them were completely confidential. The questionnaire is distributed to the respondents and given two weeks to answer the questions. The cooperation and approval to conduct this study was obtained from the Human Resources Executives of the various organizations. The questionnaire was distributed to the employees through the human resources of these organizations. Of the 200 questionnaire's, 115 questionnaires were returned completed and the remaining ones were returned unused. The final sample of this study consisted of 115 respondents.

The instrument used was a questionnaire, which tapped different measures on leadership styles and job satisfactions. It contained three sections with a total number of 36 items. This was designed by the researcher to gather information concerning the demographic data of the respondents, section 2, consists of leadership style and section 3, is the job satisfaction questionnaire items. In this study, leadership styles were measured by the multifactor leadership questionnaire, the instrument was adapted from Bass and Avolio (1990). And job satisfaction questionnaire was adapted from the Minnesota Satisfaction Questionnaire to measure the level of job satisfaction among the respondents.

\section{Results}

Table 1. Socio-demographic of respondents

\begin{tabular}{|c|c|c|}
\hline Characteristics & Frequency & Percentage (\%) \\
\hline \multicolumn{3}{|l|}{ Gender } \\
\hline Male & 65 & 56.5 \\
\hline Female & 50 & 43.5 \\
\hline \multicolumn{3}{|l|}{ Age } \\
\hline $23-28$ & 40 & 34.8 \\
\hline $29-34$ & 43 & 37.4 \\
\hline $35-40$ & 20 & 17.4 \\
\hline $41-46$ & 12 & 10.4 \\
\hline 46 and above. & - & - \\
\hline \multicolumn{3}{|l|}{ Marital status } \\
\hline Married & 70 & 60.9 \\
\hline Single & 45 & 39.1 \\
\hline \multicolumn{3}{|l|}{ Educational level } \\
\hline WAEC & 47 & 40.9 \\
\hline OND & 38 & 33.0 \\
\hline HND & 20 & 17.4 \\
\hline $\mathrm{BSC}$ & 10 & 8.7 \\
\hline \multicolumn{3}{|c|}{ Working Experience } \\
\hline$<5 \mathrm{yrs}$ & 20 & 17.4 \\
\hline $5-10 \mathrm{yrs}$ & 35 & 30.4 \\
\hline $11-15 y r s$ & 40 & 34.8 \\
\hline $16-20 \mathrm{yrs}$ & 20 & 17.4 \\
\hline \multicolumn{3}{|l|}{ Salary } \\
\hline $20,000-30,000$ & 47 & 40.9 \\
\hline $30,001-40,000$ & 38 & 33.0 \\
\hline $40,001-50,000$ & 20 & 17.4 \\
\hline $50,001 \&$ above & 10 & 8.7 \\
\hline
\end{tabular}

The characteristic of the 115 respondents in the study is shown in Table 1. Out of the 115 respondents, 65 were males and 50 were females. The age of the 115 respondents ranged from 23 years to 46 years. 70 respondents were married and 45 were single. As for their education, 47 respondents had WAEC results, 38 respondents had OND results, 20 respondents had HND results and 10 respondents had degree results. In terms of work experience, 20 respondents worked less than 5 years, 35 respondents worked between 5 to 10 years, 40 respondents worked between 11 to 15 years and 20 respondents worked between 16 to 20 years. In terms of salary, 47 respondents received between 20,000 to 30,000 per month, 38 respondents received between 30,001 to 40,000 per month, 20 
respondents received between 40,001 to 50,000 per month and 10 respondents received between 50,001 and above per month.

\subsection{Transformational Leadership Style}

Table 2. Mean scores on the dimensions of transformational leadership styles

\begin{tabular}{lll}
\hline Transformational leadership style & Mean & SD \\
\hline Idealized influence & 3.97 & 1.158 \\
I feel good being around my manager & 4.03 & 1.207 \\
I have complete faith in my manager & 3.83 & 1.384 \\
I am proud to be associate with my manager & & 1.504 \\
Inspiration motivation & 4.28 & 1.576 \\
My manager is optimistic about the future & 3.97 & 1.045 \\
My manager usually talks about what needs to be done & 3.78 & 1.276 \\
My manager always articulate about vision of the future & & 1.095 \\
Intellectual stimulation & 3.47 & 1.265 \\
May others to think about old problems in new ways & 3.33 & 1.108 \\
Give new ways on how to do our jobs & 3.33 & 1.315 \\
Solves problems in different perspectives & & 1.396 \\
Individualized Consideration & 3.83 & 3.39 \\
Spends more time in developing others & 3.78 & \\
Treats me as an individual rather than just a member of a group & & \\
Give personal attention to others that feels rejected & & \\
\hline
\end{tabular}

Table 2 below provides the mean and standard deviation scores of the four dimensions of transformational leadership styles adopted in this research. The respondents were asked to rate each of the four dimensions on a five-point scale ranging from strongly disagree (1) to strongly agree (5). As shown below, the mean scores for transformational leadership styles ranged from 3.33 to 4.28 .

\subsection{Transactional Leadership Styles}

Table 3. Mean scores on the dimensions of transactional leadership styles

\begin{tabular}{llc}
\hline Transactional leadership style & Mean & SD \\
\hline Contingent Reward & & 1.000 \\
-Specified what I will receive, if I perform very well & 3.83 & 1.253 \\
-So satisfaction when I do a good job. & 3.97 & 1.663 \\
Management - by- Exception (Active) & 3.75 & 1.885 \\
-Always pays attention on mistakes, exception and deviations from standards & 3.36 & 1.920 \\
-Always keeps track of my mistakes & 3.50 & 1.459 \\
-Spends it time looking to put out fires & 3.61 & 1.231 \\
-Pays attention toward failure to meet standards & & 1.344 \\
Management -by- Exception (Passive) & 3.36 & 3.00 \\
-Show attitudes of “if it isn't broke, don't fix it" & \\
-Only takes action only if things go wrong & & \\
\hline
\end{tabular}

Table 3 provides the mean and standard deviation scores of three dimensions of transactional leadership style adopted for this study. The mean scores are between 3.00 to 3.97. This suggests the broad agreement on the range of transactional leadership style practices used in the study. 


\subsection{Job Satisfaction}

Table 4. Mean scores on the dimensions of job satisfaction

\begin{tabular}{lll}
\hline Job satisfaction & Mean & SD \\
\hline Chance to do something that makes use of my abilities & 3.2 & 2.527 \\
Satisfy with working condition & 4.11 & 2.818 \\
Opportunity to do different things & 4.00 & 2.685 \\
Chance to do things for others people & 4.36 & 3.005 \\
Freedom to implement my own judgments & 4.00 & 3.089 \\
Being recognized for a job well done & 3.17 & 3.468 \\
Opportunity to work autonomously & 3.44 & 3.589 \\
Chance to try my own methods in doing the job & 4.03 & 3.637 \\
Chance to tell other people what to do & 4.19 & 3.740 \\
Chance for advancement on this job & 3.26 & 2.620 \\
\hline
\end{tabular}

The mean and standard deviation scores on the dimensions of job satisfaction adopted in this study are shown in Table 4 and it scores ranged from 3.17 to 4.36

\subsection{Determine the Leadership Styles that Commonly Used by the Leaders in the Organization}

Table 5. Descriptive statistics

\begin{tabular}{cccccc}
\hline & $\mathrm{N}$ & Minimum & Maximum & Mean & Std. Deviation \\
\hline Jobsatis & 115 & 2.00 & 4.88 & 3.7308 & .49081 \\
transformation & 115 & 2.09 & 5.00 & 3.9032 & .48572 \\
transactional & 115 & 2.00 & 5.00 & 3.8878 & .51052 \\
Valid N (listwise) & 115 & & & & \\
\hline
\end{tabular}

Table 6 depicts the correlation between transformational leadership style and job satisfaction.

Table 6. Correlation between transformational leadership style and job satisfaction

\begin{tabular}{lc}
\hline Leadership style & Job satisfaction \\
\hline Individualized consideration & $.604^{* *}$ \\
Intellectual stimulation & $.615^{* *}$ \\
Inspiration motivation & $.662^{* *}$ \\
Idealized influence attributed & $.627^{* *}$ \\
Contingent reward & $.504^{* *}$ \\
Management by exception (Active) & $.657^{* *}$ \\
Management by exception (Passive) & $.543^{* *}$ \\
\hline
\end{tabular}

\section{Discussion}

The objective of this research was to survey if transactional and transformational leadership styles has a relationship withemployees job satisfaction in a small and medium scale enterprisesin Nigeria. Based on previous reaserch many factors have been identified as potential factors that as a relationship with employee job satisfaction, such as sex, age, competence race and variety of skills used (Meyer \& Allen, 1997). Though, specificscholarsadvocate that evenall the same other factors are intricate, satisfaction of the employee in the organization is possibly most thoughtful of how employees feel about leaders and the performances they exhibit. Investigation in these areas has involved top management (Reichers, 1986; Becker \& Billings, 1993).

This study offers additional insight into how transformational and transactional leadership corrallate withemployees job satisfaction in an small and medium scale enterprises. From the result of correlation analysis in table 5 above, revealed all the leadership styles sub-scales are statistically significant at .05 level of significance. The result indicated that transformational and transactional leadership behaviors are important factors that contribute to employees' job satisfaction because they are positive relationship among the variables. 
This result support other research findings for example Spector, 2008, reported similar correlation among transformational leadership sub-scale. Sarror and santora also reported similar correlation in their study. Bass and Avolio (1997) also suggest correlation among the transformational and transactional sub-scales. Inspiration motivation was found to be the variable that has the highest positive correlation with .662. Leaders who display this kind of leadership styles give consideration to their followers by encouraging and coaching them to develop appropriate working behavior, (Sarror and Santora 2001). Moreover, since leaders' behavior in workplace is very important to employees' job satisfaction, they are expected to trust and have faith in the leader's decisions and actions (Sarros and Santora 2001). To the top Management in small and medium scale enterprises organization in Nigerian this is something that they can work to further encourage the employees.

To achieve the objectives two, descriptive statistics was used to determine the styles of leadership that is commonly used by the leaders in the small and medium scale enterprises in an organization in Nigeria. It was reviewed from the result that transformational leadership has the highest mean score of 3.903, which indicates that transformational leadership is the leadership styles commonly used by the leaders in the small and medium scale enterprises.

\section{Conclusions}

Overall, the determination of this reaserch was to determine the association beween the transactional and transformational leadership style and employee's job satisfaction in small and medium scale enterprises in Nigeria. The results showed that transformational leadership style and transformational leadership styles have a positive relationship with employeejob satisfaction with the organization. Therefore based on this study, leadership style that is commonly used by the leaders in the organization under study is the transformational leadership style.

The outcome of the study also buttressed earlier investigation conducted by (Mosadegh Rad \& Yarmohammadian, 2006), (Chen, 2005), (Lok \& Crawford, 1999, 2001), which revealed employee job satisfaction correlate positively with leadership styles displayed by the leader. However, based on this study, transformational leadership styles dimension of inspiration motivation had greater impact and backing than transactional leadership styles management by exception. However, this doesn't mean transactional leadership is not an important contributor to job satisfaction, the combinations of the two styles are important given circumstances and situations leaders operate.

Even though the result of the study is in line with previous researches on leadership styles and employee job satisfaction, however the need to reemphasized transformational leadership especially in Nigerian small and medium scale enterpreises becomes utmost. Furthermore, Organizations that have leadership capability to change their management approach using leadership skills will further improve their organizational performance and employees' job satisfaction.

It was also suggested that the adoption of both transformational and transactional leadership styles may increase the level of job satisfaction among the employees in small and medium-sized enterprises in Nigeria. Majority of the manager in SMEs context are also the owners of the companies. The owners/managers should not only deal directly with their employees, but also help them to create a better reinforcement system in order to motivate their employees in the SMEs situations.

\section{References}

Allen, D., \& Wilburn, M. (2002). Linking Customer and Employee Satisfaction to the Bottom Line. ASQ Quality Press, Milwaukee, WI.

Bass, B. M., \& Stogdill, R. M. (1997). Handbook of leadership, A Survey of Theory and Research. New York, Free press LTD.

Bennett, R. R. (1997). Job satisfaction among police constables: a comparative study in three developing nations. Justice Quarterly, 14(2), 295-323. http://dx.doi.org/10.1080/07418829700093341

Borders, A., Earleywine, M., \& Huey, S. (2004). Predicting problem behaviors with multiple expectancies: Expanding Expectancy Value Theory. Adolescence, 39, 539-551.

Bosman \& Nalla, M. (2009). Police organizational culture and job satisfaction: A comparison of law enforcement officers' perceptions in Two Midwestern States in the U.S. Journal of Criminal Justice and Security, 55-73.

Burns, J. M. (1978). Leadership. New York: Harper Row.

Chen, L. Y. (2005). Examining the effect of organization culture and leadership behavior on organizational 
commitment, job satisfaction, and job performance at small and medium-sized firms of Taiwan. Journal of American Academy of Business, 5, 432-438.

Furnham, A. (2005). The Psychology of behaviour at work: The individual in the organization (2nd ed.). Psychology Press, Hove \& New York.

Griffin. (1999). Creating performance management systems that promote perceptions of fairness. In J. W. Smither (Ed.), Performance appraisal: state of the art in practice (pp. 209-243). San Francisco: Jossey-Bass.

Hicks, D. S. (1987). Economic aspects of job satisfaction. In Ashenfelter, O. C., \& Oates, W. E. (Eds.), Essays in Labor Market Analysis. New York: John Wiley.

Janssen, P. P. M., Peeters, M. C. W., De Jonge, J., Houkes, I., \& Tummers, G. E. R. (2004). Specific relationships between job demands, job resources and psychological outcomes and the mediating role of negative work-home interference. Journal of Vocational Behavior, 65, 411-429. http://dx.doi.org/10.1016/j.jvb.2003.09.004

Laohavichien, P. E., \& Hogan, N. (2006). The impact of centralization and formalization on correctional staff job satisfaction and organizational commitment. Criminal Justice Studies: A Critical Journal of Crime, Law, and Society, 19, 23-44. http://dx.doi.org/10.1080/14786010600615967

Lawal, A. A. (2003). Management in Focus. Lagos: Abdul Ind. Ent.

Lok, P., \& Crawford, J. (2001). Antecedents of organizational commitment and the mediating role of job satisfaction. Journal of Managerial Psychology, 16(8), 594-613. http://dx.doi.org/10.1108/EUM0000000006302

Mosadeghrad, A., \& Yarmohammadian, M. (2006). A study of relationship between managers' leadership style and employees' job satisfaction. Leadership in Health Services, 19(2), 11-28. http://dx.doi.org/10.1108/13660750610665008

Mullins, L. (2004). Management and Organisational Behaviour. Pearson Higher Education FT Prentice Hall.

Organ, D. W., \& Konovsky, M. (1989). Cognitive versus affective determinants of organizational citizenship behavior. Journal of Applied Psychology, 74, 157-64. http://dx.doi.org/10.1037/0021-9010.74.1.157

Ostroff, C. (1992). The relationship between satisfaction, attitudes and performance: An organizational level analysis. Journal of Applied Psychology, 77(6), 963-974. http://dx.doi.org/10.1037/0021-9010.77.6.963

Sarros, J. C., \& Santora, J. C. (2001). The transformational-transactional leadership model in practice. Leadership \& Organization Development Journal, $22(8), \quad 383-394$. http://dx.doi.org/10.1108/01437730110410107

Schermerhorn, J., Hunt, J., \& Osborn, R. (2005). Organizational behaviour (9th ed.). John Willey \& Sons, Inc.

Spector, P. (2008). Industrial and organizational psychology: Research and practice (5th ed.). New York: John Wiley \& Sons.

Ting, Y. (1997). Determinants of job satisfaction of federal government employees. Public Personnel Management, 26(3), 313-34.

Worthington, I., \& Britton, C. (2006). The business environment (5th ed.). Financial Times, Prentice Hall.

Wright, B., \& Davis, B. (2003). Job satisfaction in the public sector: The role of the work environment. American Review of Public Administration, 33(1), 70-90. http://dx.doi.org/10.1177/0275074002250254

\section{Copyrights}

Copyright for this article is retained by the author(s), with first publication rights granted to the journal.

This is an open-access article distributed under the terms and conditions of the Creative Commons Attribution license (http://creativecommons.org/licenses/by/3.0/). 